\title{
Evaluation of Uncertainties in Dating of Monazite by Electron Microprobe
}

\author{
C. Merlet
}

\author{
ISTEEM, CNRS, Université de Montpellier II, P1. E. Bataillon, 34095 Montpellier cedex 5, France
}

Over the last decades, determination of ages in monazite using Electron Probe Microanalysis (EPMA) has progressed to the point that it is now considered as a routine procedure within several laboratories worldwide [1,2]. Nevertheless, the typical age errors of individual electron probe spots reported in the literature are an order of magnitude larger than attainable by Secondary Ion Mass Spectrometry (SIMS) and two orders of magnitude larger than attainable by Thermal Ionization Mass Spectrometry (TIMS). The age errors frequently range from $40 \mathrm{Ma}$ to $120 \mathrm{Ma}$, although after statistical treatment of a set of homogeneous ages, a precision of approximately $20 \mathrm{Ma}$ can be obtained. Despite the low accuracy, the numerous studies have shown that the Th-U-totalPb method using the EPMA is a reliable method, easy to use, for detecting age variations on a very small scale. The effective limitation of the EPMA monazite ages determination concerns its relatively poor accuracy regarding mainly $\mathrm{Pb}$ determination. Similarly the relative uncertainties for $\mathrm{U}$ and $\mathrm{Th}$ are generally larger than $2 \%$, which can lead to large errors. The error on the age for each analysed point depends on the $\mathrm{U}$, Th and $\mathrm{Pb}$ concentration. As the $\mathrm{Pb}$ concentration is directly related to the age of the monazite and to the $U$ and $T h$ concentration, older is the monazite, better is the relative error. Since the first monazite dating study by EPMA [1] there has been improvements in data age processing, but only few evaluations of uncertainties in the $\mathrm{Pb}, \mathrm{U}$, Th determinations. As the error calculated on the age for each analysed point is the whole inaccuracies on $\mathrm{Pb}, \mathrm{U}$, Th determinations, this method requires high accuracies determinations of trace elements [3] as well as of major elements.

The aim of the present experimental and theoretical study is firstly for evaluating precisely the uncertainties of EPMA dating of monazite and secondarily to give suggestions for minimizing them. Precise evaluation is not straightforward because sources of uncertainties include not only counting statistic but also many parameters like microprobe operating conditions (e.g., accelerating voltage, beam current, beam diameter, pulse height analyser), spectral background subtraction, quantification procedure, overlap, line shape, standards, sample preparation (polish, carbon coat, contamination), irradiation damage etc.. To estimate experimentally these sources, measurements were done on a large homogeneous monazite from the Itambe pegmatite district (Brazil [4]). The crystal homogeneous at the micrometer scale is free of fluid and solid inclusions. The composition (6.5 wt. $\% \mathrm{Th}, 0.12 \mathrm{wt}$. $\% \mathrm{U}$ and $0.15 \mathrm{wt} . \% \mathrm{~Pb}$ ) is typical for natural monazites. Multiple Isotope Dilution Thermal Ionisation Mass Spectrometer (IDTIMS) analyses yield concordant U-Pb ages of $474 \pm 1$ $\mathrm{Ma}$ [5] and document the isotopic homogeneity of the monazite. The precise knowledge of age and the low $\mathrm{Pb}$ and $\mathrm{U}$ content in this monazite allows us to estimate the main sources of uncertainties in age determination using EPMA. As the decay constant is lower for $U$ than Th, the lower is the $U$ concentration, the higher is the difficulty in the age determination. As an example for this monazite, $1 \%$ deviation on $\mathrm{Th}$ concentration induces an age error of $5 \mathrm{Ma}, 30 \mathrm{ppm}$ deviation on $\mathrm{Pb}$ concentration produces an age error of $10 \mathrm{Ma}$ and $130 \mathrm{ppm}$ deviation on $\mathrm{U}$ concentration produces an age error of $5 \mathrm{Ma}$. 
For Th and, in general way, for major elements when an accuracy better than $1 \%$ is required, all parameters (apparatus, sample, quantification procedure etc..) become significant. When high accuracy is required together, for major and trace elements, the narrow dynamic of the microprobe increases the difficulties. It must be emphasized that the determination of all major elements in addition to $\mathrm{U}, \mathrm{Th}$, and $\mathrm{Pb}$ is essential to detect sample defects (inclusions, surface roughness, contamination) or other common problem. In addition, quantification procedure, which takes into account $\mathrm{X}$-ray production and emission, requires to be accurate the determination of all elements in the sample (e.g., P, REEs, Y, etc.). Uncertainty in quantification depends of calculation procedure [6], which is related to accelerating voltage, standards and atomic parameters used (e.g., mass absorption coefficients). When absorption is important, the uncertainty on one element can induce significant uncertainties on other elements. As a consequence, all concentrations determinations have to be done carefully for minimizing the dependence of other elements on the calculated age.

At the trace level $(\mathrm{Pb}, \mathrm{U})$, apart from common sources of uncertainties, the background subtraction, interferences and other spectrum aspects become important for concentrations determinations. For the $\mathrm{Pb} \mathrm{M} \alpha$ line, the base line of the $\mathrm{Th} \mathrm{M} \zeta_{1}$ and second order diffraction of $\mathrm{La} L \alpha$ line can induce a large error in the background subtraction. In addition, the most serious spectral interference arises from superposition of $\mathrm{Y} L \gamma_{2,3}$. Subtractions require precise determinations of overlapping elements for computing the corresponding spectrums overlapping lines. However, these difficulties can be removed by measuring the $\mathrm{Pb} \mathrm{L} \alpha$ line. This line is totally free of interferences and has low matrix effect, but induces a loss of spatial resolution and a decrease of accuracy on Th quantification due to the high accelerating voltage required. For U, on commercial WDS EPMA, only M lines are available for the measurement. As for $\mathrm{Pb} \mathrm{M} \alpha$ line, the main difficulty concerns the background subtraction because of the presence of secondary Th and Nd lines throughout the spectrum and the Ar absorption edge for proportional counter filled with Ar.

In this study, analyses were performed on a Cameca SX 100 EPMA equipped with five wavelengthdispersive spectrometers. To check discrepancy in $\mathrm{Pb}$ determination, $\mathrm{Pb}$ was simultaneously measured with M $\alpha$ line (LPET crystal) and L $\alpha$ line (LLIF crystal). To examine specific effects or bias, accelerating voltage and beam current ranging between 15 to $30 \mathrm{kV}$ and 100 to $500 \mathrm{nA}$ were used respectively. To estimate precisely the background subtraction and interferences and to consider specific effects (reflectivity of the analyzer crystal or edge resulting of mass absorption coefficients in the sample or in the detector), we used a more elaborated procedure that combines spectrum measurements and simulations [7]. Similarly, for standards, to estimate the effect of the quantification calculation versus accelerating voltage, acquisition procedure or inaccuracy of the composition, various standards were used.

\section{References}

[1] K. Suzuki and M.J. Adachi, Geochem. J. 25 (1991) 357

[2] J.M. Montel et al., Chem. Geol. 131 (1996) 37

[3] C. Merlet and J.L. Bodinier, Chem. Geol. 83 (1990) 55

[4] M.J. Cruz et al., XXXIX Congresso Brasileiro de Geologia, vol. 2. Sociedade Brasileira de Geologia-Nucleo, Bahia-Segipe, (1996) 206

[5] A. M. Seydoux-Guillaume et al., Chem. Geol. 191 (2002) 165

[6] C. Merlet, Mikrochimica Acta 114/115 (1994) 363

[7] F. Kalfoun et al., Mikrochimica Acta 139 (2002) 83 